\title{
Horizontal Nystagmus and Homonymous Hemianopia due to Lateral Geniculate Body Hemorrhage
}

\author{
Young-Su Han Eugene Lee Jong S. Kim \\ Stroke Center and Department of Neurology, University of Ulsan, Asan Medical Center, Seoul, South Korea
}

Dear Sir,

Patients with lateral geniculate body (LGB) stroke usually show contralateral homonymous hemianopia [1]. To our knowledge, however, horizontal nystagmus has never been reported in these cases. Here, we report such a patient.

\section{Case Report}

A 51-year-old hypertensive man suddenly developed visual disturbances. On examination, he showed a left homonymous hemianopia (fig. 1a) and a spontaneous right-beating nystagmus. Other neurologic examination findings were unremarkable. Results from the Weber and Rinne tests, the Dix-Hallpike test and pure-tone audiometry were normal. Ocular motor movements were grossly intact and there was no saccadic slowing. In video oculography, the vestibulo-ocular reflex gain in both horizontal and vertical directions was measured, and the interaction of head shaking and nystagmus was examined during a reading task. Eye and head coordination during attempted gaze changes was evaluated to examine vestibulo-ocular reflex gain changes and any strategies employed to compensate for decreased vestibular function. The examinations did not reveal any abnormalities except for a spontaneous and a right gazeevoked nystagmus. An optokinetic nystagmus (OKN) examination by the rotational chair test showed that the left-beating nystagmus was reduced when the strips were moved towards the right side. In a caloric test, the left-beating nystagmus was suppressed when visual fixation was performed after cold-water irritation on the right external ear canal. However, the right-beating nystagmus was not suppressed after cold-water irritation on the left side. In addition, there was a mildly increased gain in the visual-fixation test on the rotational chair. These findings were suggestive of visual-fixation dysfunction due to a right cerebral lesion (fig. $1 b-f$ ). A computed tomography scan of the brain showed an intracerebral hemorrhage involving the right LGB (fig. 1g). The nystagmus gradually resolved in 3 days, when the patient's OKN also normalized. However, his visual-field defect remained unchanged after 40 days of follow-up.

\section{Discussion}

In our patient, various tests showed that the peripheral vestibular function and vestibulo-ocular reflex were intact. The OKN results from the rotational chair tests suggested ipsilateral, horizontal, smoothpursuit dysfunction, which seemed to cause left-conjugate eyeball deviation and a compensatory right-beating nystagmus. Visual fixation, equivalent to the smooth

\section{(For figure see next page.)}

Fig. 1. a Humphrey 30-2 visual-field test shows a complete left homonymous hemianopia. b There is a spontaneous right beating nystagmus (fixed: $6 \%$; darked: $9 \%$ ) with a right gaze-evoked nystagmus in the video oculography. The optokinetic nystagmus examination by rotational chair (c) shows that the left beating nystagmus is reduced when the strips move in the clockwise direction $(40 \% \mathrm{~s})$ as compared to when the strips move counterclockwise. In the caloric test (d), the left beating nystagmus is suppressed from $23 \%$ to $10 \%$ when visual fixation is presented after right external ear canal cold water irritation. However, the right beating nystagmus shows no interval change after left cold water irritation. Also, there is a mildly increased gain in the visual fixation test on rotational chair (e). The vestibulo-ocular reflex is normal (f). g. A CT of the patient's brain shows localized intracerebral hemorrhage in the right lateral geniculate body.

\section{KARGER}

Fax +4161306 1234 E-Mail karger@karger.ch www.karger.com
Jong S. Kim, MD, PhD

Department of Neurology, Asan Medical Center

388-1 Pungnap-2 dong, Songpa-gu

Seoul 138-736 (South Korea)

Tel. +82 23010 3442, Fax +82 2474 4691, E-Mail jongskim@amc.seoul.kr 


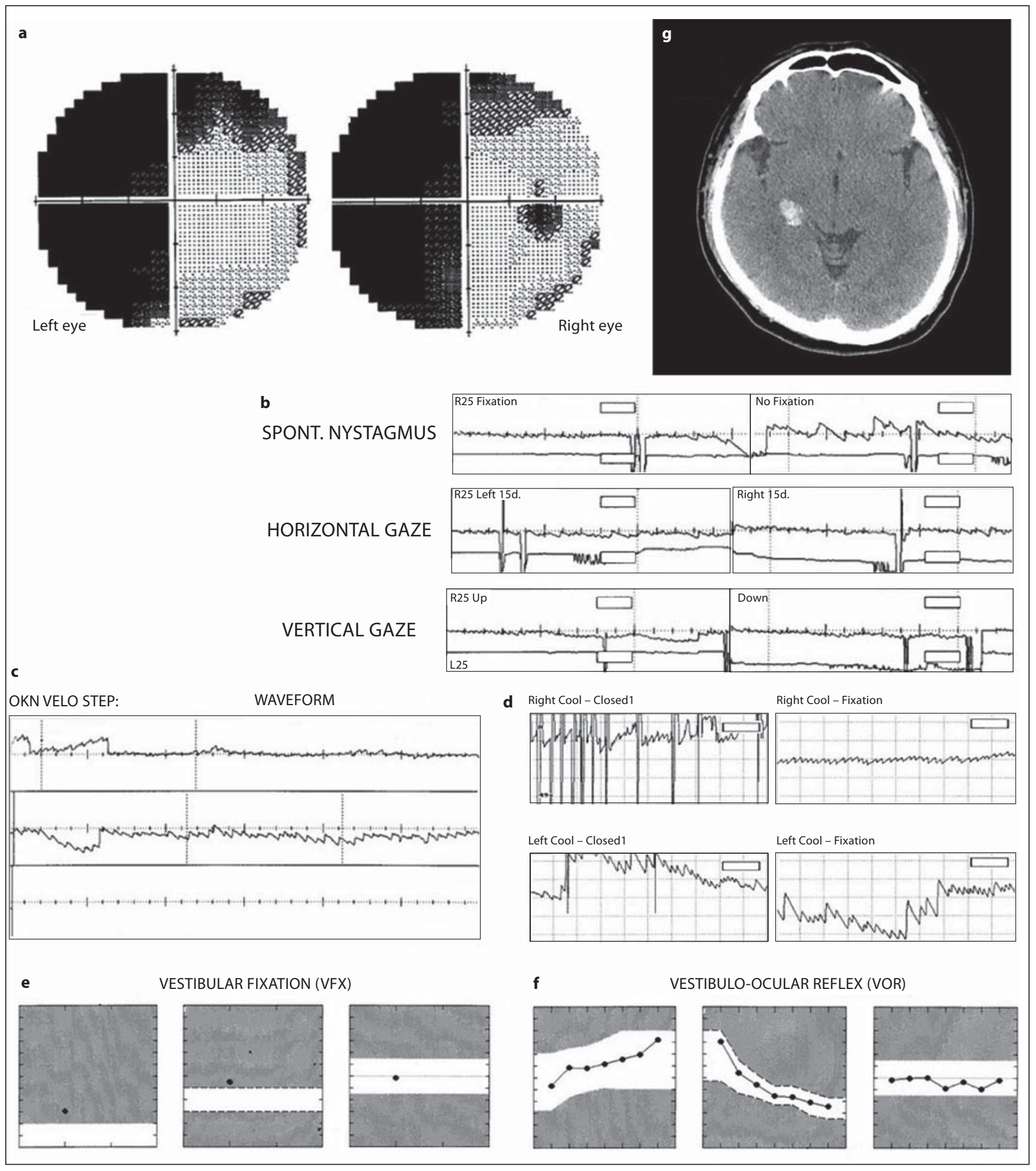


pursuit of a target moving at zero velocity [2], also seemed impaired in our patient. Thus, the nystagmus may be related to the visual fixation disorder due to the interruption of the right, horizontal, smoothpursuit pathway by LGB hemorrhage.

It has been shown that electrical stimulation of the LGB produces a contraversive horizontal nystagmus in experimental animals $[3,4]$. There are 2 functional divisions of the visual system in the LGB. The $\mathrm{M}$ layer is involved in the projection of moving stimuli detected by the retinal ganglion to the visual cortex, while the $\mathrm{P}$ layer is involved in projecting features of a particular object to a different visual cortex [2]. When both $\mathrm{M}$ and $\mathrm{P}$ layers representing an identical part of the visual field are destroyed, animals cannot locate a target or initiate smooth-pursuit eye move- ments, while lesions that selectively involve the $\mathrm{M}$ pathway damage the smoothpursuit system only partially and rarely produce a nystagmus $[2,5]$. Therefore, the thresholds for producing nystagmus and hemianopia seem to be different in subjects with LGB lesion, which might explain why the horizontal nystagmus resolved earlier than the homonymous hemianopia in our patient.

\section{Acknowledgement}

This study was supported by a grant from the Brain Research Center of the 21st Century Frontier Research Program, which is funded by the Ministry of Science and Technology of Korea (M103KV010010 06K2201 01010).

\section{References}

1 Brazis PW, Masdeu JC, Biller J: Localization in Clinical Neurology, ed 4. Philadelphia, Lippincott Williams \& Wilkins, 2001, pp 145-159.

2 Leigh RJ, Zee DS: The neurology of eye movements, ed 4. New York, Oxford University Press, 2006, pp 188-240.

-3 Gutman J, Bergmann F, Chaimovitz M, et al: Nystagmus evoked by stimulation of the optic pathways in the rabbit. Exp Neurol 1963; 8:132-142.

4 Schiff D, Cohen B, Raphan T: Nystagmus induced by stimulation of the nucleus of the optic tract in the monkey. Exp Brain Res 1988;70:1-14

5 Page WK, King WM, Merigan W, et al: Magnocellular or parvocellular lesions in the lateral geniculate nucleus of monkeys cause minor deficits of smooth pursuit eye movements. Vision Res 1994;34:223-239. 